\title{
Comunistas, judíos y demás ralea, de Pío Baroja. Nuevas aportaciones y precisiones a su génesis, edición y recepción por los medios
}

\author{
Miguel Ángel GARCÍA DE JUAN \\ IES "Rosa Chacel", Madrid \\ somi.85@hotmail.com
}

\section{RESUMEN}

Todavía en estos tiempos en que se ha aclarado y precisado la mayoría de los aspectos de la vida y obra de Pío Baroja se sigue incurriendo en errores por no acudir o no hacer caso a investigaciones más o menos recientes.

Una falta de rigor que se comete con frecuencia es la referida a la fecha de publicación de la antología barojiana confeccionada y manipulada por José Ruiz Castillo Comunistas, judios y demás ralea. Por tanto, en el presente artículo se aportan nuevos datos a los que ya se expusieron en el prólogo de Libertad frente a sumisión, Pío Baroja, 2001, que, extraídos de un rastreo más minucioso de la prensa de 1938, corroboran, precisan y amplían en mayor medida lo dicho allí: la salida a la luz de aquel libro de don Pío pasada la primera mitad del tercer año de la última guerra civil española.

Uno de los aspectos que quieren destacarse en este artículo se refiere a que los medios republicanos prestaron más atención a la mencionada antología espuria de Pío Baroja para desacreditarla que los nacionales para promocionarla. De ello se desprende, una vez más, que don Pío no contó con la estimación de unos ni de otros ni se inclinó con convicción hacia ninguno bando, aunque tuviera que atravesar coyunturas enojosas para poder sobrevivir en momentos totalmente condicionados por la política y en medio de estrecheces económicas.

Otro asunto destacable por su novedad tiene que ver con la más que probable principal causa de la existencia de Comunistas, judios y demás ralea: las aludidas estrecheces económicas de Baroja, de las que también quiso obtener provecho pecuniario (y político) el que trazó el proyecto de su publicación, o sea, el editor José Ruiz Castillo.

Palabras clave: Pío Baroja, Comunistas, judíos y demás ralea, medios republicanos, medios nacionales. 


\begin{abstract}
Nowadays, when almost all the points about Baroja's life have been clarified and specified, some errors are still maintained for not paying attention to more or less recent investigations.

A frequent lack of rigor appears in relation with the publication date of Baroja's anthology, made and manipulated by José Ruiz Castillo Comunistas, judios y demás ralea. That is why this article adds new pieces of information to those already offered in the prologue to Libertad frente a sumisión, Pío Baroja, 2001. These facts, drawn from a very detailed study of the press in 1938, elaborate and corroborate what is said in the mentioned prologue. One of the most important aspects in this work has to do with the fact that the Republican media payed more attention to the mentioned and spurious anthology in order to discredit it than the National media in order to promote it, and, as a consequence again, Baroja neither counted on the republican's esteem nor the national's, not leaning with conviction towards any wing, although he had to go through annoying circumstances so as he could go on living in a time absolutely conditioned by politics and by shortage of money.

Other remarkable and new issue is referred to the main and more than probable cause to the existence of Comunistas, judios y demás ralea: the said Baroja's economic difficulties from which the publisher, the editor José Ruiz Castillo, who drew the publishing project, wanted to obtain some economical and political benefit.
\end{abstract}

Key words: Pío Baroja, Comunistas, judíos y demás ralea, Republican media, National media.

Hace ya tiempo que tratamos en el prólogo a Libertad frente a sumisión, de Pío Baroja, 2001, de las distintas partes que componen su bastarda antología Comunistas, judios y demás ralea (1938), el proceso de elaboración y la fecha aproximada de publicación ${ }^{1}$.

Llama poderosamente la atención que después de largos años de haber expuesto de forma razonada en el aludido prólogo la fecha más aproximada de la publicación de Comunistas [...], la cual es básica para conocer quién tuvo la ocurrencia de

${ }^{1}$ «Prólogo» de Libertad frente a sumisión, P. Baroja (2001), pp. 92-102. Todavía en 2002, aunque el «Preludio» esté firmado en Vitoria el 8 de agosto de 2001, antes de la salida a la luz de Libertad frente a sumisión, se leen afirmaciones como ésta: «A pesar de las maniobras de Ernesto Giménez Caballero, autor del prólogo y antólogo en un alucinado e "irresponsable" volumen titulado Comunistas, judios, masones (sic) y demás ralea [...], esta mancha hizo, desde luego, un flaco servicio al nombre del novelista», Á. Martínez Salazar (2002), p. 343. 
publicarlo, el proceso de su elaboración, quién fue el verdadero responsable de su estampación y su repercusión en uno y otro bando de la guerra civil, se haya hecho y se siga haciendo caso omiso de lo dicho allí, salvo en raras excepciones ${ }^{2}$. En consecuencia, causa sorpresa que más o menos distinguidos estudiosos de la vida y obra de Pío Baroja continúen cometiendo yerros al afirmar lo que mejor les parece, sin aportar una razón sólida.

Para el recientemente fallecido Fernando Pérez Ollo «En marzo [de 1938] salió de la imprenta Comunistas, judios y demás ralea, de Pío Baroja» ${ }^{3}$; asimismo en 2006 afirmaba Miguel Sánchez-Ostiz que «en el mes de marzo aparecía en Valladolid uno de los libros más comprometidos de Pío Baroja, Comunistas, judios y demás ralea, de la mano de José Ruiz-Castillo Franco, el editor de Biblioteca Nueva» ${ }^{4}$. Un año después el propio Sánchez-Ostiz repetía casi las mismas palabras en Tiempos de tormenta (Pío Baroja 1936-1940): «En el mes de marzo de 1938 aparecía en Valladolid el libro más comprometido de Pío Baroja: Comunistas, judios y demás ralea. Lo haría de la mano de José Ruiz-Castillo Franco, el editor de Biblioteca Nueva» ${ }^{5}$. En el año 2009, Antonio Martín Puerta afirmaba en relación con las ideas de Baroja que «publicaría durante la guerra el pintoresco intelectual falangista Ernesto Giménez Caballero una arbitraria síntesis barojiana con el título de Comunistas, judios y demás ralea» ${ }^{6}$. Por su parte, Antonio Regalado manifestaba en 2011 con total desembarazo que encontró «en una librería de viejo de Nueva York una colección de textos espumados de la obra del novelista y publicados en Burgos (sic) en 1938 [...] con el título de Comunistas, judíos y demás ralea» ${ }^{7}$. Ese mismo año 2011, Carlos Roberto Saz Parkinson, en su estudio Positivamente negativo. Pío Baroja ensayista aseveraba que el «libro fue publicado por primera

\footnotetext{
${ }^{2}$ Véase J. C. Ara Torralaba (2002), p. 228. Véase, asimismo, J. Mª Marín Martínez (2010), pp. 55-56.

${ }^{3}$ F. Pérez Ollo (2006), p. 792.

${ }^{4}$ M. Sánchez-Ostiz (2006), p. 354.

${ }^{5}$ M. Sánchez-Ostiz (2007), p. 180.

${ }^{6}$ A. Martín Puerta (2009), p. 43. Igualmente, a mediados de este año 2009, sin comprometerse con el mes de su publicación, E. Giustiniani incurría en el tópico de atribuir al Robinson literario de España la formación de la antología, y en la inexactitud en cuanto a su composición, con estas palabras: «Ese mismo año [1938], Ernesto Giménez Caballero publicó, juntando pasajes de sus obras [las de Baroja] el ominoso tratado de Masones (sic), judios y demás ralea» (2009), p. 16.

${ }^{7}$ A. Regalado (2011), p. 50. No se entiende cómo se puede afirmar que el libro fue editado en Burgos. Pero es que, además, por lo que se dice en la página 51, parece haberse leído el prólogo de Libertad frente a sumisión sin hacer caso a unas informaciones y aprovechando otras, mas siempre sin citarlo.
} 
vez en Valladolid en 1938 por partidarios de Franco» ${ }^{8}$. El error de Regalado en cuanto al lugar de la publicación del libro de Baroja y su imprecisión respecto al momento de su salida a la luz, y la inconcreción de Saz Parkinson acerca de cuándo se puso a la venta Comunistas, judio y demás ralea resultan muy llamativos por cuanto dedican a esta antología del escritor vasco varias páginas y no parece que desconozcan nuestro reiterado prólogo de Libertad frente a sumisión. Finalmente, José-Carlos Mainer en Pío Baroja, 2012, quien como Pérez Ollo y Sánchez-Ostiz ofrece referencias expresas al reiterado prólogo, manifiesta con mayor precaución que los anteriores que «el libro misceláneo de Baroja [...] apareció bajo el sello de la editorial Reconquista en la primavera de $1938 »{ }^{9}$.

Registradas aquí todas estas manifestaciones respecto a la fecha de publicación del libro recopilatorio de Pío Baroja, pasamos a resumir en pocas líneas lo expuesto en el prólogo de Libertad frente a sumisión, información si no ignorada, si desestimada o silenciada por no se sabe qué motivos.

Decíamos en el repetido prólogo de 2001 que el editor Ruiz Castillo tenía en principio la intención, quizá por sugerencia de Ernesto Giménez Caballero, de publicar convenientemente manipulados a favor del bando nacional varios escritos de Pío Baroja anteriores al comienzo de la guerra civil, pero, como no había cerrado completamente el proyecto y Baroja estaba publicando diversos artículos en la España rebelde y en el extranjero, pensó que algunos podían encajar en su proyecto propagandístico y tomó, para editarlos en la primera parte de la antología, algunos aparecidos en el primer trimestre de 1938, el último de ellos «Condición actual de las aldeas», procedente de El Norte de Castilla del día 1 de marzo. A su vez, la antología Comunistas, judios y demás ralea, formada en su segunda parte por textos anteriores a la guerra y extraídos de otras antologías, novelas y el diario Ahora ${ }^{10}$, anunciaba que se hallaba en prensa Aire, tierra y mar, libro de José García Mercadal, cuyo contenido concluía el 18 de julio de 1938. En consecuencia, el libro recopilatorio de Baroja (y Ruiz Castillo) tuvo que ver la luz en torno a esa fecha. El último argumento que aportábamos era que la revista bimensual Occident, órgano de la España rebelde en París desde octubre de 1937, insertaba en su número del 25 de septiembre de 1938 una crítica favorable de Comunistas, judios y demás ralea firmada por Manuel García Blanco en la que repetía que este libro acababa de publicarse.

${ }^{8}$ C. R. Saz Parkinson (2011), p.139. Es la traducción de su tesis doctoral presentada en la Universidad de Columbia en 2007. Saz Parkinson falleció dramáticamente en agosto de 2008, a los treinta y ocho años de edad.

${ }^{9}$ J.-C. Mainer (2012), p. 336. Del contenido y silenciamiento de fuentes de un libro sobre Baroja publicado en enero de 2008 en Pamplona, es preferible no emitir una opinión.

${ }^{10}$ Véanse el prólogo a Libertad frente a sumisión, ed. cit., pp. 97-98 y la nota 117 de de dicho prólogo. 
Pues bien, como gran parte de los estudiosos de la vida y obra de Pío Baroja parece no haber leído o soslayado los argumentos enumerados, queremos aportar en este artículo el resultado de nuestra investigación más reciente que ratifique, amplíe y precise lo expuesto en el prólogo de Libertad frente a sumisión, por si a nuevos interesados en el escritor guipuzcoano les parce oportuno ajustarse lo más posible a la realidad de los hechos cuando se refieran a Comunistas, judios y demás ralea, puesto que, como ya se dijo, su data encierra una estrecha relación con el proceso de elaboración de la antología y el responsable material de la recopilación y manipulación de los escritos de Pío Baroja. Creemos que se puede decir ahora, (casi) con toda seguridad, que la responsabilidad de todo no fue de otro que del editor Ruiz Castillo.

Estimamos oportuno detenernos en este punto, ya que tiene gran interés el artículo de Raquel Sánchez García «José Ruiz-Castillo, editor de la Edad de Plata (1910-1945)», 2002, por lo que respecta a la información en cuanto a las empresas editoriales creadas por él ${ }^{11}$. Recuerda la autora que Ruiz Castillo fundó la editorial Renacimiento en Madrid en 1910, a lo que añadimos nosotros que en ella publicó Pío Baroja ya en ese mismo año César o nada; en 1911, nada menos que Él árbol de la ciencia y Las inquietudes de Shanti Andía; el año siguiente, El mundo es ansí; pero es que, además de esta primeras ediciones, sólo hasta 1913, vieron la luz con el mismo sello varias segundas estampaciones de novelas del autor vasco. Volviendo al artículo de Raquel Sánchez, informa ésta de que, tras abandonar Renacimiento, Ruiz Castillo pasó a ejercer de gerente de la revista España y luego, al dimitir Ortega y Gasset de la dirección, se hizo cargo de ella interinamente, puesto en el que lo sustituyó Luis Araquistain en 1916. Cabe agregar a esto, aunque sea conocido, que Baroja fue desde el principio uno de los redactores del semanario, el cual ya en el primer número insertó una colaboración suya, hasta que abandonó la revista con la llegada a la dirección del citado Araquistain. En 1917 Ruiz Castillo fundó la editorial Biblioteca Nueva, en la que no publicaría nada Baroja, pues ese mismo año su cuñado Rafael Caro Raggio había creado la suya y en ella comenzó a estampar, junto a otras, las de la familia; sin embargo, desaparecida esta casa editora como consecuencia de la guerra, Pío Baroja publicaría sus Obras completas (realmente incompletas y censuradas) en la citada Biblioteca Nueva. Y es que la relación entre Ruiz Castillo y el escritor no se interrumpió nunca. En efecto, la guerra civil sorprendió al primero en La Granja de San Ildefonso, desde donde se trasladó a Valladolid, ciudad en la que se instaló y comenzó a trabajar para la editorial Santarén. Con todo, su vocación de editor lo condujo a crear su propio sello con el nombre de Reconquista, con el que publicó, como es sabido, Comunistas, judíos y demás ralea de Pío Baroja y otras obras acordes con las ideas de los nacionales. A este propósito manifiesta Raquel Sánchez en su citado trabajo:

\footnotetext{
${ }^{11}$ R. Sánchez García (2002).
} 
Aunque había tratado con importantes personajes republicanos [...], aborrecía lo que consideraba excesos revolucionarios. Sus simpatías debían de estar, por tanto, con aquellos que se levantaron contra el gobierno legítimo. En una carta al escritor José María Salaverría [18 de diciembre de 1937], escribió unas palabras muy elocuentes acerca de su postura: «Ansío poder poner mi grano de arena al Movimiento salvador de nuestro país $\mathrm{y}$, como lo único que puedo hacer son libros, estoy preparando una pequeña colección de ellos dedicados a distintos aspectos de nuestro Movimiento, teniendo la suerte de contar ya con varios ofrecimientos de imprentas y autores para realizar mis propósitos». ${ }^{12}$

De lo expuesto en el párrafo y cita anteriores, de lo que declaró a Raimundo Bartrés su hermano Ricardo Baroja acerca de que toda la responsabilidad de la antología la tuvo el editor, de lo que afirmó don Pío sobre la indiferencia que le causó la antología $^{13}$, de la inclinación congénita de Ruiz Castillo a publicar libros recopilatorios y de la conclusión a la que llega también Raquel Sánchez: «Esta publicación fue, al parecer, idea del propio Ruiz-Castillo», cabe sostener con mínimas posibilidades de error que el responsable de todo fue el editor de Reconquista, de quien acaso se pueda decir, después de lo que venimos exponiendo, que más que aceptar el ofrecimiento de un artículo de Giménez Caballero (quien pudo no estar muy lejos pero no dedicó ni una palabra en sus numerosos artículos a hacer propaganda de la antología) para que le sirviera de prólogo, se lo solicitó a éste. En efecto, José Ruiz Castillo debió de aprovechar su buena relación con Baroja desde muchos años atrás, las estrecheces económicas por las que atravesaba el escritor y su vuelta a Vera de Bidasoa, o sea, a zona nacional, en septiembre de 1937, para obtener un beneficio pecuniario y compartirlo con don Pío, a la vez que intentaba demostrar que el escritor guipuzcoano se hallaba claramente del lado de los sublevados, con lo que podía llevar una vida tranquila en la citada localidad navarra $^{14}$. No obstante, Baroja decidió regresar al exilio francés en febrero de 1938 ,

\footnotetext{
12 R. Sánchez García (2002), pp. 136-137.

13 «Prólogo» a Libertad frente a sumisión, ed. citada, pp. 96-102. De las necesidades económicas, de los temores congénitos de Baroja a carecer de dinero y de su total falta de atención a Comunistas, judios y demás ralea, incluido el título, es prueba la carta a su hermana Carmen del 24 de septiembre de 1939 en la que dice que va a reeditar la antología la editorial Santarem (sic). Baroja parece ignorar todavía en 1939 que Ruiz Castillo desde el año anterior ya no trabajaba en Santarén sino que había creado su propia editorial en la que había publicado la primera edición de Comunistas, judíos y demás ralea. Véanse las páginas 101-102 del aludido prólogo.

${ }^{14}$ No se puede olvidar, es cierto, la participación de Julio Caro Baroja en esta historia. Con todo, su interés en ella debió de ser muy escaso, pues ni recuerda el título correcto ni conoce bien de qué está compuesta la antología: «Uno de los hechos que más le perjudicaron en esta hora triste fue, por ejemplo, la aparición en Valladolid, en 1938, de un libro hecho con
} 
al sentirse en desacuerdo y advertir que perdía su libertad si se dejaba introducir en el mundo ideológico y político en que pretendían incluirlo.

Para encontrar nuevos datos en los medios escritos que corroboren, aumenten y afinen, como venimos haciendo, lo dicho en el prólogo de Libertad frente a sumisión hemos rastreado con más atención aún que en 2001 numerosas publicaciones periódicas de uno y otro bando contendientes en la última guerra civil española de los meses de abril a septiembre de 1938, por varios motivos. En primer lugar porque la antología incluye, como se ha dicho antes, un artículo del mes de marzo de ese año. En segundo término, porque Pío Baroja desde muy pronto fue objeto de ataques desde los medios republicanos al haberse exiliado en Francia y escribir artículos para La Nación de Buenos Aires en los que censuraba más a la República y sus políticos que a los sublevados. Así, el diario caballerista Claridad, que ya el 22 de Julio de 1936 había publicado un suelto bajo el título «La enorme soledad de don Pío», siguió con sus ataques de tal modo que el 4 de agosto insertaba otro suelto con el marbete de «Pío Baroja, el padre Gafo y Dios» en el que lamentaba que los carlistas no hubieran acabado con el escritor el día 22 del pasado mes. Por su parte, el periódico republicano La Voz del 6 de enero de 1937 declaraba: «Una generación que no comprende [...]. Pío Baroja duda en Buenos Aires». Y el día siguiente el $A B C$, también de Madrid, terminaba una columna sin nombre del autor: «El lanzador de explosivos»:

Sí, Baroja, sí; era un explosivo. Lo que sucede es que usted y los de su generación creían que las ideas no lo tienen, porque solo veían en ellas un asunto de pintoresca y vaga literatura. Mas una juventud sin escepticismos, afrontando las consecuencias máximas del momento actual en el mundo, ha recogido esas ideas que ustedes manejan, sin responsabilidad y de prestado, y ha empezado a lanzarlas contra los instintos de los que no tienen ninguna. ${ }^{15}$

Asimismo, La Libertad del 19 de marzo, en su página cuarta, lo motejaba de «arrepentido»y «sinvergüenza».

Por su parte, Enrique López Alarcón lo acusaba en Solidaridad Obrera del 29 de septiembre de ese año de «germanófilo vergonzante», y $L a$ Voz volvía al ataque el 25 de octubre en un artículo de Juan López Núñez que trataba del mecánico Luis

fragmentos de otros suyos (sic) que lleva el título de Comunistas, judios, masones y demás ralea. Puedo decir ahora que la selección no la hizo él, que el título tampoco es suyo y que la correspondencia mía de entonces con mi tío y con el editor es suficiente para probar que fui yo el que sirvió de mediador en un asunto editorial que se presentó de una manera y resultó de otra», Semblanzas ideales, J. Caro Baroja (1972), p. 48. En realidad el texto en el que aparecen estas palabras del sobrino del escritor es un artículo de 1962 titulado «Pío Baroja. Recuerdos», llevado luego al citado libro.

${ }^{15}$ Estos y otros ataques desde medios de la izquierda pueden leerse en el reiterado prólogo de Libertad frente a sumisión, ed. cit., p. 43 y ss. Los de $A B C$ y posteriores se añaden ahora. 
Morer, al que comparaba con «Silvestre Paradox» y del que decía que era «un tipo que Baroja podría estudiar si no se hubiera hecho fascista» ${ }^{16}$.

La tercera razón para rastrear con mayor atención la prensa de uno y otro bandos se fundamenta en que los rebeldes se hallaban muy interesados en contar con el favor de los intelectuales famosos en distintos campos: ciencia, pensamiento, literatura, música...

Con este fin utilizaron recursos como evitar ataques a la manera de pensar y actuar de Baroja (arremetidas que sí venían haciendo los republicanos), invitarlo a asistir inexcusablemente a la constitución del Instituto de España en Salamanca el 6 de enero de 1938, contratarle artículos durante la interrupción de su exilio en Vera de Bidasoa, colaboraciones que el autor hubo de ver rodeadas de noticias sobre el catolicismo y (o) el carlismo, y poco o nada más, a no ser algunas iniciativas personales como las de Ruiz Castillo o el pintor Roberto Martínez Baldrich, quien le publicaría la novela Susana y alguna que otra creación. Con todo, Baroja mantuvo su independencia por encima de los reclamos y artimañas de unos o los reproches y agresiones verbales de otros.

Así pues, situados en el mes de abril del tercer año de la última guerra civil, la columna diaria sin firma «Tiro al blanco» del periódico $L a$ Voz del día 5 se titulaba insultante «Un mangante con boina» y manifestaba que don Pío se encontraba del lado de aquellos a los que tanto había criticado en sus escritos. Al mismo tiempo, esta columna lanzaba un «Aviso a los libreros» para que retiraran de la venta las obras de Baroja. ¿Cabe deducir de esta sugerencia o advertencia del periódico que le habían llegado ya rumores o noticias de que se iba a publicar Comunistas, judios $y$ demás ralea?

En el barrido que hemos realizado de los periódicos entre los meses citados (abril-septiembre de 1938) hemos encontrado las siguientes huellas de que la antología iba a publicarse o había salido ya a la luz hacía muy poco tiempo, todas ellas centradas en los últimos días de junio y el mes de julio. El diario republicano barcelonés La Vanguardia del 28 de junio aludía a la antología del escritor vasco en una columna de su página tercera firmada por «GENIL» en la que se atacaba ferozmente a don Pío por no haberse opuesto a la sublevación militar, haber acudido a Salamanca el 6 de enero y «según rezan las noticias más frescas, escribir un libro en el que se exalta la brutalidad y toda la miseria de esa España que a nosotros nos duele en lo más hondo y que a los traidores les suena ya a calderilla sucia en los bolsillos». A lo que añade:

Lo mismo que un día entró por la Academia besando amatistas y faldones troglodíticos, después de haberse pasado los años y las vigilias escribiendo contra las niñerías académicas, ahora se ha entrado por las puertas de la España

\footnotetext{
${ }^{16}$ Solidaridad Obrera, Barcelona, 29 de septiembre de 1937, p. 3; La Voz, Madrid, 25 de octubre de 1937, pp. 1-3.
} 
vendida e invadida, tras haber expresado incontables repulsas a esa ralea (la cursiva es nuestra) despreciable que hoy la detenta. Bueno será recordar que Baroja fue en un tiempo amigo de Lerroux y que llegó, incluso, a ser concejal (sic) lerrouxista. ${ }^{17}$

Dejando al margen el error (¿malintencionado?) de que Pío Baroja fue concejal durante su breve militancia en el Partido Radical, hay varios datos que apuntan directamente a la publicación inmediata de Comunistas, judios y demás ralea, uno de los cuales consiste en la presencia en esta columna del sustantivo final del título de la antología: «ralea», pero aplicado al bando nacional.

El mismo día 28 el periódico republicano barcelonés El Diluvio insertaba en su primera página un suelto con el título «El eclipse de un hombre» cuyos primeros párrafos dicen:

Pío Baroja no está inactivo. Pío Baroja, que hubo de recurrir a los más audaces y arriesgados procedimientos para hurtar su vida, al comienzo de la sublevación, a la ferocidad carlista, escribe actualmente un libro difamando a España.

¡Triste condición la de este escritor que en el ocaso de su vida tiene que poner toda la crudeza de su pluma, que, cuando quiere, hiere como un agudo estilete, al servicio de los traidores a su Patria! ${ }^{18}$

El día siguiente, el 29, el diario anarquista Solidaridad Obrera, también de Barcelona, publicó un suelto titulado «Tal para cual. Baroja y sus aberraciones seniles», que nada más empezar alude igualmente a Comunistas, judios y demás ralea:

Baroja va a escribir un libro. Lo habrá escrito ya. El panadero novelista anarquista, hombre malo de Itzea, lerrouxista y académico de la lengua, está al servicio de la causa de Franco, de Italia y de Alemania [...]. Sus libros de la primera época, que pretenden ser revolucionarios, no pasan de ser más que unas pobres masturbaciones de un hombre que busca un camino y unos señores que le paguen su persistencia en andarlo [...]. Baroja, don Pío, se pronunció por el fascismo y por los verdugos de España apenas iniciada la rebelión. Persiste en esta actitud. A nosotros no nos duele ni poco ni mucho. Para ellos todo. Al fin y al cabo, tales para cuales. ${ }^{19}$

\footnotetext{
${ }^{17}$ GENIL, «De un momento a otro. Una vida y su epílogo », La Vanguardia, Barcelona, martes 28 de junio de 1938, p. 3.

${ }^{18}$ El Diluvio, «El eclipse de un hombre», Barcelona, martes 28 de junio de 1938, p. 1.

${ }^{19}$ Solidaridad Obrera, Barcelona, 29 de junio de 1938, p. 8. No deja de llamar la atención que en los último diez años haya habido y siga habiendo personas hostiles a Baroja que emplean, si no términos iguales, sí muy subidos de tono, al referirse a él.
} 
Parece, por tanto, que a El Diluvio y Solidaridad Obrera también les habían llegado noticias de la próxima salida de Comunistas, judios y demás ralea si no de su presencia ya en las librerías y reaccionaban con esta feroz acometida contra su autor, ataque que continuó el segundo el día 3 de julio bajo el título de «Los muertos que andan. Pío Baroja», cuyo primer párrafo rezaba:

Se viene hablando ya demasiado de este vejestorio, de este saldo literario que nos legara la desdichada «Generación del 98». Se le ha dado demasiada importancia a este viejo chocho, cuya principal manía consiste en desentonar del común de los mortales para labrarse -él, casariego y comodón empedernido- una aureola de individuo independiente, cuando la realidad, la vergonzosa realidad, nos descubre la poca hombría del sujeto.

Y concluye con estas palabras tan tremendas: «Una cuerda suspendida en un árbol a veces vale por un poema. ¿Qué esperas, Baroja, para escribir el último capítulo sincero de tu vulgarísima vida? ${ }^{20}$

Terminados los ataques implícitos a Comunistas, judíos y demás ralea y expresos a su autor, solo queda el silencio en los medios del bando republicano, mientras sí hallamos el 12 de julio de 1938 en el diario vallisoletano El Norte de Castilla la reseña sin firma «Un libro de Baroja. Comunistas, judios y demás ralea» cuyas primeras líneas dicen:

Baroja es de los que nunca dudan, ni vacilan en salir al palenque cuando el deber lo pide y aun sería más verdad si dijéramos que en el palenque está desde hace muchos años, peleando contra el enemigo más poderoso de nuestro tiempo con una tenacidad solo igualada por la clarividencia de los males a cuyo paso sale y del remedio que pueden tener.

El autor de este escrito aparecido en el periódico continúa refiriéndose al prólogo de Ernesto Giménez Caballero, a las partes de que consta el libro, a los distintos textos de cada una y concluye diciendo que, como es imposible en el diario hacer un examen minucioso de la antología, se trata solo de una orientación para el lector. Y finaliza: «Si Comunistas, judíos y demás ralea alcanza el éxito de público que merece, será enorme» ${ }^{21}$.

Cabe la posibilidad de que esta reseña en El Norte de Castilla de la antología de Baroja ya publicada o a punto de publicarse la escribiera el propio Ruiz Castillo, al tratarse de un empeño personal, pues su relación con el periódico vallisoletano debió de ser franca y habitual, si se considera que tomó de él varios artículos de don

${ }^{20}$ «Los muertos que andan. Baroja», Solidaridad Obrera, Barcelona, 3 de julio de 1938, p. 2.

${ }^{21}$ «Un libro de Pío Baroja. Comunistas, judíos y demás ralea», El Norte de Castilla, martes 12 de julio de 1938, p. 7. 
Pío para insertarlos en Comunistas, judio y demás ralea, incluido el citado «Condición actual de las aldeas» del 1 de marzo de $1938^{22}$.

Sin embargo, una recensión, también sin firma, como la de El Norte de Castilla, pero sin estar llamativamente mutilada en casi la mitad de su extensión ni algo modificada al comienzo, la hemos hallado en dos periódicos nacionales: Imperio (Zamora), 15 de julio, y El avisador numantino (Soria), 27 de julio ${ }^{23}$. ¿Disponía el diario vallisoletano de menos espacio que los de Zamora y Soria y por eso amputó parte de la reseña?

A los poco avisados puede dejarles perplejos que en la zona republicana, reducida a menos de una tercera parte de la que se encontraba en poder de los nacionales, hubiera proporcionalmente más referencias al libro, aunque fueran tácitas, para atacarlo, que en los medios nacionales, para dar noticia de su aparición o hacer publicidad y propaganda de él, pues consultada más de una veintena de publicaciones de la zona sublevada, comprendidos bastantes de los medios que insertaron artículos del escritor vasco durante su interrupción del exilio, ninguno de ellos hace una recensión de él o lo menciona, a excepción de los ya conocidos: $E l$ Norte de Castilla, Imperio, El avisador numantino y Occident, este ya fuera de España $^{24}$, a los que añadimos un quinto que no sólo confirma la aparición de Comunistas, judíos y demás ralea en el mes de julio sino que facilita la respuesta al porqué de su escaso eco en la prensa del bando nacional. Nos estamos refiriendo al periódico carlista de Vitoria Pensamiento Alavés, el cual, los días 19, 28 y 30 de julio de 1938, en su columna titulada «Con pluma ajena» atacaba frontalmente a la antología, al autor del forzado prólogo y a Pío Baroja. La del día 19, centrada casi entera en el mencionado prólogo de Ernesto Giménez Caballero, decía al comienzo y al final:

${ }^{22}$ También La Gaceta Regional de Salamanca publicó varios de estos artículos, incluido este último, dos días después de que lo hiciera El Norte de Castilla. Pero con el título diferente de «La aldea y la ciudad baja».

${ }^{23}$ Imperio, 19 de julio de 1938, p. 4; El avisador numantino, 27 de julio de 1938, 2 . El Noticiero (Zaragoza), en el apartado «Libros y revistas» del 20 de julio de 1938, p. 10, publica, junto a la reseña de otros tres libros, la correspondiente a Comunistas, judios y demás ralea, pero reducida a menos de una cuarta parte respecto a la de Imperio y El avisador numantino.

${ }^{24}$ Entre la más de una veintena de periódicos que hemos examinado en los fondos de la Hemeroteca Municipal de Madrid sin hallar rastro de la antología de Baroja se encuentran los principales de la zona nacional: La Gaceta Regional (Salamanca), Diario Regional y Libertad (Valladolid), Diario de Navarra (Pamplona), La Voz de Galicia (La Coruña), Región (Oviedo), Norte (Vitoria), La Tarde (Santa Cruz de Tenerife), La Falange (semanario, Cáceres), HOY (Badajoz), Heraldo de Aragón y Amanecer (Zaragoza), La Gaceta de África (Tetuán), F.E., ABC y El Correo de Andalucía (Sevilla) y Diario Vasco (San Sebastián). En periódicos como los tres últimos hay, de vez en cuando, anuncios y crítica de libros, pero el silencio sobre Comunistas, judíos y demás ralea es bien elocuente. 
Pío Baroja ha puesto, estos días, en las librerías un libro titulado. «Comunistas, judíos y demás ralea». Y el libro lleva un prólogo de Jiménez (sic) Caballero cuyo final es así literalmente hablando de la obra «César o nada» de Baroja.

[...] Nos parece preciso decir -y lo decimos- que ese galimatías que arma con Cisneros, Baroja, Loyola, Nietzsche, Soreil (sic) y la Academia Española no es de recibo. Siquiera para evitar confusionismos. Pero, además, séanos lícito decir que, para nosotros, es más del tiempo viejo la generación del 98 a la que pertenece Baroja que el siglo de oro en que vivió Cisneros, Y nada más. ${ }^{25}$

La columna del día 28 se centra en el contenido de algunos artículos de la antología y manifiesta:

Esto dice Baroja en un libro editado ahora en Valladolid con prólogo de Jiménez (sic) Caballero. [...] Después de esto sólo nos resta decir que es de muy baja ralea el confusionismo que usa Baroja en el libro de venta en estos días. ${ }^{26}$

Finalmente, la columna del 30 copia lo que ha escrito de Comunistas, judios y demás ralea su correligionario El Pensamiento Navarro, de la que transcribimos el último párrafo:

$\mathrm{Y}$ en cuanto a Baroja, mientras no conozcamos -y no los conocemos- actos nuevos suyos, repetiremos la frase de nuestro querido colega «Arriba España»: «Contra el impío, contra el clerófobo... no queremos nada con Baroja». ¡Sólo queremos que se convierta y viva! ${ }^{27}$

La conclusión a la que se llega una vez más, tras lo expuesto hasta aquí, es que los republicanos mantuvieron hacia don Pío una indisimulada animadversión y los otros intentaron sin tener ninguna seguridad atraerlo a sus dominios, cuando no lo atacaron por sus opiniones respecto a la religión y el clero. Sin embargo, hay que insistir en que el proyecto concreto de la publicación de Comunistas, judios y demás ralea semeja algo muy personal de José Ruiz Castillo. Esto explica su marginación casi total, tras haberse publicado en julio de 1938, en los medios del bando

${ }^{25}$ Pensamiento Alavés, 19 de julio de 1938, p. 4.

${ }^{26}$ Pensamiento Alavés, 28 de julio de 1938, p. 1.

${ }^{27}$ Pensamiento Alavés, 30 de julio de 1938, p. 4. Aún no había regresado Pío Baroja a España de su segundo período de exilio, cuando el diario Labor, «Órgano de la Falange Española Tradicionalista y de la JONS» publicaba un artículo el 7 de mayo de 1940, 8, «La chochez de don Pío», en el que, criticando el de este en La Nación de Buenos Aires titulado «Los sistemas totalitarios», decía: «[...] donde el pobre don Pío manifiesta una vez más no conocer el cristianismo y donde demuestra poseer los más exiguas nociones del fascismo o de lo totalitario, a pesar de su flamante Judíos, marxistas y demás ralea (sic), y a pesar del prólogo de Giménez Caballero [...]». 
nacional, disconforme con la nueva salida de Baroja al exilio cinco meses antes, en busca de libertad para hacer y decir lo que le pareciera oportuno, independencia de la que no podía disfrutar en España, por no encontrarse de acuerdo con «los hunos» ni con «los hotros», como diría Unamuno ${ }^{28}$. Puesto que aludimos al pensador bilbaíno, tal vez resulte oportuno señalar que, mientras en nuestro rastreo de los medios nacionales no hemos hallado, salvo en la media docena citada, alusiones a Baroja ni a sus obras entre abril y septiembre de 1938, sí hemos visto cómo en $E l$ Correo de Andalucía y en varios más el «Servicio Nacional de Propaganda de la Falange Española Tradicionalista y de las JONS» se anunciaban entre las obras de José Antonio Primo de Rivera, Onésimo Redondo, Raimundo Fernández Cuesta, Ernesto Giménez Caballero o Eugenio D'Ors, antologías de Donoso Cortés, el padre Mariana, Ganivet... y Unamuno. Y es que el intento de utilización de personas de prestigio vivas o muertas en beneficio del bando nacional, que es al que nos estamos refiriendo ahora, no tuvo límites.

\footnotetext{
${ }^{28}$ Respecto al fastidio que ocasionó a los nacionales la segunda marcha de Baroja a Francia traemos aquí el significativo caso de la reacción del semanario donostiarra Domingo. El periodista Luis Antonio de Vega había entrevistado a Baroja en Vera de Bidasoa en su interrupción del exilio, entrevista que publicó dicho semanario el 6 de marzo de 1938, cuando el escritor vasco estaba de nuevo en el país vecino, a la que siguió una semana después el artículo de don Pío «La crisis del hogar». Pues bien, la revista dirigida por Juan Pujol no volvió a tratar de nada relacionado con Pío Baroja, incluida la antología Comunista, judios y demás ralea, aun cuando los artículos de Ernesto Giménez Caballero ocuparan con frecuencia las páginas del semanario y ésta dedicara cada cierto tiempo un espacio a «El Rincón de los Libros», que en varios casos reseñaba publicaciones de la editorial vallisoletana Santarén. A este punto llegó la frustración de los nacionales, lo repetimos, como consecuencia de la nueva marcha a Francia de Baroja a mediados de febrero de 1938.

Por lo que hace referencia a las citadas palabras de Unamuno, véase la carta «A Quintín de Torre», 1 de diciembre de 1936, M. de Unamuno, (1991), pp. 350-352: «Entre unos y otros o mejor, los hunos y los hotros- están ensangrentando, desangrando, arruinando, envenenando y entonteciendo a España», p. 351.
} 


\section{Obras citadas}

ARA TORRALBA, Juan Carlos: «Baroja, impiedades textuales», en Los textos del 98, Universidad de Valladolid, 2002, pp. 181-234.

BAROJA, Pío: Comunistas, judíos y demás ralea, Valladolid, Reconquista, 1938.

CARO BAROJA, Julio: Semblanzas ideales, Madrid, Taurus, 1972.

GARCÍA DE JUAN, Miguel Ángel: «Prólogo» a Libertad frente a sumisión, Pío Baroja, Madrid, Caro Raggio, 2001, pp. 7-128.

GIUSTINIANI, Eve: «El exilio de 1936 y la tercera España. Ortega y Gasset y los blancos de París, entre franquismo y liberalismo», Circunstancia, año VII, N ${ }^{\circ}$ 19, mayo, 2009, pp. 1-18.

MAINER, José-Carlos: Pío Baroja, Madrid, Taurus, 2012.

MARÍN MARTÍNEZ, Juan María: «Introducción» a La busca, Pío Baroja, Madrid, Cátedra, 2010, pp. 13-221.

MARTÍN PUERTA, Antonio: Ortega y Unamuno en la España de Franco, Madrid, Ediciones Encuentro, 2009.

MARTÍNEZ SALAZAR, Ángel: El señor de Itzea. Apuntes para una geografía barojiana, Madrid, Biblioteca Nueva, 2002.

PÉREZ OLLO, Fernando: «La última salida», en Desde la última vuelta del camino. Memorias, Pío Baroja, Barcelona, Tusquets, 2006, vol. III, pp. 791-795.

REGALADO, Antonio: Leyendo a Baroja, Sevilla, Renacimiento, 2011.

SÁNCHEZ GARCÍA, Raquel: «José Ruiz-Castillo, editor de la Edad de Plata (1910-1945)», Castilla, 27, 2002, 123-140.

SÁNCHEZ-OSTIZ, Miguel: Tiempos de tormenta (Pio Baroja, 1936-1940), Pamplona, Pamiela, 2007.

SÁNCHEZ-OSTIZ, Miguel: Pío Baroja, a Escena, Madrid, Espasa Calpe, 2006.

SAZ PARKINSON, Carlos Roberto: Positivamente negativo. Pio Baroja ensayista, Madrid, Editorial Complutense, 2011.

UNAMUNO, Miguel de: Epistolario inédito (1915-1936), ed. Laureano Robles, Madrid, Espasa Calpe, 1991.

\section{Periódicos citados}

ABC, El avisador numantino, Claridad, El Diluvio, Imperio, Labor, La Libertad, El Norte de Castilla, Pensamiento Alavés, El Pensamiento Navarro, Solidaridad Obrera, La Voz. 